\title{
ЦИФРОВИЗАЦИЯ ПРОЦЕССОВ АКТИВИЗАЦИИ ГОСУДАРСТВЕННО-ЧАСТНОГО ПАРТНЕРСТВА КАК ИНСТРУМЕНТ ПРИВЛЕЧЕНИЯ ИНВЕСТИЦИЙ
}

\author{
Т.А. Аверина, С.А. Баркалов, Ю.С. Лаврова \\ Воронежский государственный технический университет, г. Воронеж, Россия
}

\begin{abstract}
В настоящее время одним из перспективных направлений развития экономики является цифровизация в целом и формирование качественной информационной инфраструктуры в частности. Особенно это актуально для процессов активизации государственно-частного партнерства - взаимовыгодного взаимодействия государства и бизнеса. В связи с пандемией инвесторы работают со своим портфелем более осторожно, и привлекать частные средства становится сложнее. Целью исследования является анализ информационной среды для ГЧПпроектов, а именно оценка ее привлекательности и прозрачности для инвесторов. Задачами являются анализ распределения концессионных соглашений по объему инвестиций, выявление проблемных зон в реализации программ государственно-частного партнерства РФ, описание мероприятий, способствующих повышению эффективности государственно-частного взаимодействия. В работе применялись общенаучные методы анализа и синтеза, а также экономико-статистический и сравнительный методы. Авторы опирались на такие материалы, как актуальные публикации отечественных и зарубежных ученых по теме исследования, материалы всероссийских и международных конференций по управлению, электронные отчеты исследовательских центров и официальную статистику, представленную государственными органами. В качестве результатов приводится описание интерактивной карты-рейтинга городов по уровню развития проектной деятельности в сфере государственно-частного партнерства. Интерактивная карта - это мощный инструмент цифровой трансформации, в отличие от ежегодных публикуемых электронных и бумажных отчетов точнее отражает ситуацию на рынке ГЧП проектов в текущий момент времени, то есть информация остается актуальной для каждого запроса каждого последующего пользователя. Также в статье приводятся результаты сравнительного анализа популярных картографических программ для определения наиболее эффективной и устойчивой платформы для создания сервиса. Преобразуя таким образом традиционную информационную инфраструктуру, можно повысить инвестиционную привлекательность субъектов, а следовательно, повлиять на уровень качества жизни жителей как отдельных городов, так и всей страны.

Ключевые слова: государственно-частное партнерство, инвестиционная привлекательность, циировизация, интерактивные картыл.
\end{abstract}

\section{Введение}

В настоящее время ключевым направлением развития мировой экономики является внедрение цифровых технологий во все сферы жизни общества [1-3]. Локдаун 2020 года, связанный с ограничениями из-за распространения короновирусной инфекции, показал, что автоматизация, оптимизация и перевод процессов из оффлайна в онлайн - единственно верный путь к построению гибкого технологичного общества.

Более того, мировой кризис затронул и инвестиционную сферу. Сегодня инвесторы работают со своим портфелем не так активно, а более осторожно. Поэтому для привлечения инвестиций теперь необходимо прилагать еще больше усилий, создавая более комфортные условия, в том числе удаленно в онлайн-системах $[4,5]$. Это обуславливает особую актуальность темы исследования.

Сотрудничество государства с частным бизнесом на взаимовыгодных условиях - это ключевое направление решения общественно значимых задач во время пандемии. Целью данной работы является анализ доступности, привлекательности и прозрачности информационной среды в сфере государственно-частного партнерства. Для достижения этой цели необходимо решить следующие задачи: выделить основные проблемные зоны в отношении информационной инфра- 
структуры для успешного сотрудничества государства и бизнеса, проанализировать возможные пути решения выявленных проблем, рассмотреть математическую модель расчета уровня развития ГЧП в городах по критерию опыта реализации таких проектов, проанализировать, какой способ автоматизации составления рейтинга для привлечения инвестиций наиболее актуален.

Анализ сформированности качественной информационной среды для ГЧП-проектов

Государственно-частное партнерство является перспективным взаимодействием государства и бизнеса. Для одной стороны это возможность сокращения бюджетных расходов в условиях сложной экономической ситуации, а для другой - обеспечение возврата вложенных инвестиций. Но так как в РФ такое взаимодействие пока что достаточно ново, существует ряд факторов, тормозящих привлечение частных средств.

По состоянию на февраль 2020 года объем принятых инвестиционных обязательств по заключенным концессионным соглашениям составляет порядка $1,6 \%$ от объема ВВП [6]. Для сравнения отметим, что в Великобритании этот уровень составляет $6,6 \%$ в Новой Зеландии и Австралии - 6,9\%, а в Канаде - 8,1 \% от ВВП [6]. Эти данные свидетельствуют о недостаточном уровне инвестиций в российскую инфраструктуру посредством активизации процессов государственно-частного партнерства.

Что касается отечественного рынка крупных концессионных соглашений, то здесь на 2020 год заключено всего 32 соглашения с объемом инвестиций от 10 млрд руб. и 93 соглашения с объемом инвестиций от 1 до 10 млрд руб. [6].

Наглядно объем инвестиций представлен на рисунке.

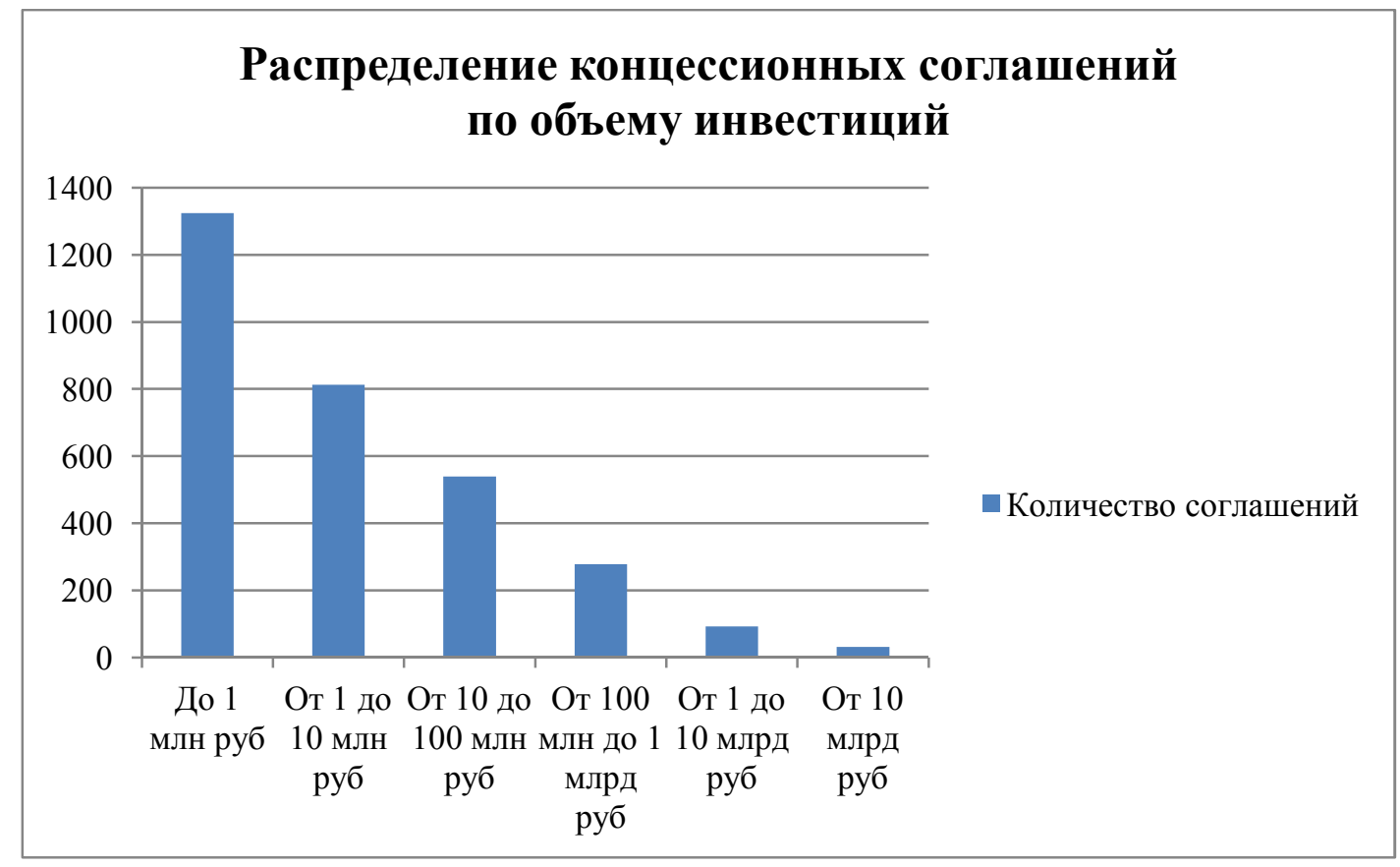

Распределение концессионных соглашений по объему инвестиций Distribution of concession agreements by investment volume

В глобальном смысле это очень небольшие значения. Привлечь большой объем инвестиций свыше 10 млрд руб. является сложной задачей ввиду текущего несовершенства как нормативного, так и информационного электронного сопровождения [7].

Рассмотрим проблемные зоны государственно-частного партнерства в РФ:

- отсутствие полных структурированных рекомендаций для частных инвесторов и публичной стороны по инициированию и реализации проектов ГЧП;

- отсутствие утверждённого порядка межведомственного взаимодействия на всех этапах жизненного цикла ГЧП-проектов;

- нехватка специалистов соответствующей квалификации в сфере ГЧП; 


\section{Управление в социально-экономических системах}

- недостаточное количество информации о развитии, целях и наличии вспомогательных материалов в сфере ГЧП;

- отсутствие единого доступного и активного интернет-сервиса, осуществляющего полное и качественное информационное сопровождение и привлечение инвесторов [7].

Опираясь на выделенные проблемные зоны, а также на материалы исследований Национального Центра ГЧП, можно сформировать основные рекомендации для развития в городах эффективного государственно-частного партнерства (табл. 1).

Рекомендации для развития в городах государственно-частного партнерства

Таблица 1

Recommendations for the development of public-private partnerships in cities

\begin{tabular}{|c|c|c|}
\hline $\begin{array}{c}\text { № } \\
\Pi / \Pi\end{array}$ & Рекомендованные мероприятия & Описание \\
\hline 1 & $\begin{array}{l}\text { Проведение мероприятий по соз- } \\
\text { данию максимально комфортной } \\
\text { информационной среды для по- } \\
\text { тенциальных инфраструктурных } \\
\text { инвесторов }\end{array}$ & $\begin{array}{l}\text { Рекомендуется разместить на официальном сайте субъ- } \\
\text { екта или на иных общедоступных ресурсах подробную } \\
\text { информацию о приоритетах и целевых индикаторах } \\
\text { применения механизмов ГЧП, мерах поддержки, реали- } \\
\text { зуемых на территории субъекта проектах ГЧП и ус- } \\
\text { пешных практиках, а также перечень объектов, в отно- } \\
\text { шение которых планируется заключение концессий и } \\
\text { соглашений о ГЧП }\end{array}$ \\
\hline 2 & $\begin{array}{l}\text { Определение } \text { уполномоченного } \\
\text { органа в сфере ГЧП }\end{array}$ & $\begin{array}{l}\text { Рекомендуется выбрать ответственных по рассмотре- } \\
\text { нию частной концессионной инициативы и законода- } \\
\text { тельно закрепить регламент их работы }\end{array}$ \\
\hline 3 & $\begin{array}{l}\text { Утверждение порядка межведом- } \\
\text { ственного взаимодействия на всех } \\
\text { этапах жизненного цикла ГЧП- } \\
\text { проектов }\end{array}$ & $\begin{array}{l}\text { Рекомендуется системно подойти к регламентированию } \\
\text { отношений участников ГЧП на стадиях разработки, } \\
\text { рассмотрения, принятия решения о реализации, осуще- } \\
\text { ствления контроля, надзора, мониторинга и ведения } \\
\text { реестра проектов ГЧП }\end{array}$ \\
\hline 4 & $\begin{array}{l}\text { Разработка и популяризация обра- } \\
\text { зовательных программ по теме } \\
\text { ГЧП }\end{array}$ & $\begin{array}{l}\text { Рекомендуется уделять внимание этому направлению в } \\
\text { образовании с целью повышения успешности ведения } \\
\text { переговоров местными проектными командами с по- } \\
\text { тенциальными инвесторами для запуска проектов ГЧП }\end{array}$ \\
\hline 5 & Применение ГЧП-фильтра & $\begin{array}{l}\text { Рекомендуется проводить на этапах планирования и } \\
\text { структурирования обязательное обоснование выбора } \\
\text { оптимальной формы реализации инфраструктурных } \\
\text { проектов и целесообразности использования механиз- } \\
\text { мов ГЧП }\end{array}$ \\
\hline
\end{tabular}

Наиболее остро в кризис стоит вопрос цифровизации максимально возможного количества процессов во всех сферах экономики, поэтому в данной статье особое внимание уделено именно направлению развития информационной среды, которая будет прозрачна, доступна и всегда активна для запросов пользователя - потенциального инвестора.

Описание модели интерактивного рейтинга городов по уровню развития ГЧП

Говоря о создании информационной среды, важно обратить внимание на важность размещения в интернете рейтинга субъектов РФ по уровню развития ГЧП. Он представляет собой результаты расчетов по такому ключевому фактору, как опыт реализации ГЧП-проектов в конкретном городе, и является важнейшим элементом инвестиционной привлекательности.

Расчет его значения производится по формуле

$E_{j}=k_{j} \cdot \sum_{\substack{i=1 \\ k=1}}^{n, m}\left(\varepsilon_{j i k} \cdot \ldots \cdot \varepsilon_{j n m}\right)$, 
где $n$ - общее количество рассматриваемых критериев;

$m$ - общее число реализованных ГЧП-проектов;

$\varepsilon_{j i k}-$ значение $i$-го критерия фактора опыт реализации для $k$-го проекта в сфере государственно-частного партнерства, $\varepsilon_{j i k}=[0-1,5]$;

$k_{j}$ - коэффициент отраслевой дифференциации проектов [4].

Значение последнего коэффициента определяется следующим образом:

- для проектов, реализуемых в одной отрасли, $k=1,0$;

- для проектов, реализуемых в двух отраслях, $k=1,1$;

- для проектов, реализуемых в трех отраслях, $k=1,2$;

- для проектов, реализуемых в четырех отраслях и более, $k=1,3$ [8-10].

В настоящее время для публикации отчета-рейтинга городов по уровню развития ГЧП привлекаются специалисты - эксперты Национального центра ГЧП. Рейтинг публикуется на официальном сайте каждый год.

Целесообразно сделать данный рейтинг автоматизированным, чтобы на определенной онлайн-платформе отображалось актуальное положение городов не раз в год, а обновлялось на текущий момент времени. Другими словами, рекомендуется заменить публикацию ежегодного рейтинга в pdf-формате на современную интерактивную карту состояния развития ГЧП в городах РФ. Это позволит дополнительно мотивировать администрации субъектов использовать различные механизмы ГЧП для привлечения частных инвестиций в развитие инфраструктуры. Более того, автоматизация способствует повышению информационной открытости ввиду аккумулирования в открытом доступе информации, которая необходима для запуска максимально возможного количества проектов ГЧП.

Автоматизированная интерактивная карта представляет собой электронную карту, функционирующую в режиме двухстороннего диалогового взаимодействия человека (пользователя) и компьютера, при визуальном чтении которой можно получить заложенную информацию о конкретных объектах $[10,11]$.

Информация, которую в один клик может получить пользователь (инвестор) оперативно, «считывая» такую карту:

1) общую степень готовности институциональной среды и управленческих команд в городах для реализации ГЧП-проектов;

2) сводный перечень приоритетных проектов в городах с указанием сроков, предпочтительной формой реализации, ответственных органов и т. д.;

3) возможные меры поддержки, а также предоставляемые льготы.

Создавать интерактивные карты можно на базе трех основных специализированных программ. Информация об их сравнительных характеристиках представлена в табл. 2 [12-14].

Сравнительные характеристики картографических программ

Таблица 2

Comparative characteristics of map programs

Table 2

\begin{tabular}{|c|c|c|c|}
\hline $\begin{array}{c}\text { № } \\
\Pi / \Pi\end{array}$ & Название & Описание & Формат \\
\hline 1 & MapInfo & $\begin{array}{l}\text { Электронная географическая информаци- } \\
\text { онная система (ГИС), которая предназна- } \\
\text { чена для сбора, хранения, отображения, } \\
\text { редактирования и анализа пространст- } \\
\text { венных данных. Выпущено расширение } \\
\text { МарInfo Pro, разработанное специально } \\
\text { для создания, обработки, визуализации и } \\
\text { анализа растровых поверхностей }\end{array}$ & $\begin{array}{l}\text { Поддерживает в Microsoft Excel, } \\
\text { Ассеss, форматы реляционных и } \\
\text { пространственных баз данных } \\
\text { (Oracle, Microsoft SQL Server, } \\
\text { PostGIS, SQLite), форматы гра- } \\
\text { фических данных (AutoCAD } \\
\text { DXF/DWG, SHP, DGN) и др. }\end{array}$ \\
\hline
\end{tabular}




\section{Управление в социально-экономических системах}

Окончание табл. 2

Table 2 (End)

\begin{tabular}{|c|c|c|c|}
\hline $\begin{array}{c}\text { № } \\
\Pi / \text { ח }\end{array}$ & Название & Описание & Формат \\
\hline 2 & Panorama & $\begin{array}{l}\text { Универсальная геоинформационная сис- } \\
\text { тема, имеющая средства создания и ре- } \\
\text { дактирования цифровых карт и планов } \\
\text { городов, обработки данных ДЗ3, выпо- } \\
\text { нения различных измерений и расчетов, } \\
\text { оверлейных операций, построения 3D- } \\
\text { моделей, обработки растровых данных, } \\
\text { средства подготовки графических док-- } \\
\text { ментов в цифровом и печатном виде, а } \\
\text { также инструментальные средства для } \\
\text { работы с базами данных }\end{array}$ & $\begin{array}{l}\text { Допускается импорт векторных } \\
\text { карт из форматов (SXF, TXF, } \\
\text { OGC GML (XML), KML (Google), } \\
\text { Arinc 424 и экспорт карт в форма- } \\
\text { ты SXF, MIFLMID, SHPDBF } \\
\text { (Shape), OGC GML (XML), KML } \\
\text { (Google), DXF, S57 }\end{array}$ \\
\hline 3 & MicroStation & $\begin{array}{l}\text { Программное обеспечение для модели- } \\
\text { рования и визуализации инфраструктур- } \\
\text { ных проектов любого типа, размера и } \\
\text { сложности с помощью комплексного на- } \\
\text { бора инструментов проектирования для } \\
\text { надежной реализации даже самых мас- } \\
\text { штабных проектов }\end{array}$ & $\begin{array}{l}\text { MicroStation DGN. Основывается } \\
\text { также на формате Intergraph } \\
\text { Standard File Format (ISFF) или } \\
\text { более новом стандарте V8 DGN } \\
\end{array}$ \\
\hline
\end{tabular}

Создание подобных интерактивных карт не только повысит инвестиционную привлекательность субъектов, но и позволит в будущем сформировать эффективную единую онлайнплощадку по обмену опытом в сфере ГЧП, а также внедрить систему удаленного мониторинга реализуемых в конкретный момент времени ГЧП-проектов [15-17].

\section{Заключение}

В данной работе были проанализированы основные проблемные зоны в отношении сотрудничества государства и бизнеса в РФ, детально описаны возможные мероприятия для решения выявленных проблем, приведена математическая модель расчета уровня развития ГЧП в городах по критерию опыт реализации ГЧП-проектов, что является важным компонентом формирования инвестиционной привлекательности, а также обозначено наиболее эффективное направление в автоматизации составления рейтинга для привлечения инвестиций - создание интерактивной карты.

\section{Лuтература}

1. Аверина, Т.А. Анализ возможностей ицифровой трансформации управления жилищнокоммунальным хозяйством на примере онлайн-сервисов / Т.А. Аверина, Ю.С. Лаврова, Л.П. Мышовская // Теория активных систем - 50 лет: материалы междунар. науч.-практ. конф., 2019. C. 290-297.

2. Авдеева, Е.А. Интерактивные карты как элемент ичфровой инфраструктуры жилищнокоммунального хозяйства / Е.А. Авдеева, Т.А. Аверина, Ю.С. Лаврова // Теория и практика экономики и предпринимательства: тр. ХVIII Всерос. с междунар. участием науч.-практ. конф. Симферополь, 2021. - С. 199-201.

3. Механизмы принятия решений в иифровой экономике / С.А. Баркалов, В.Н. Бурков, О.С. Перевалова, Т.А. Аверина // Тенденции развития интернет и иифровой экономики: тр. III Всерос. с междунар. участием науч.-практ. конф. - 2020. - C. 12-16.

4. Технологическое предпринимательство. С чего начать - первые шаги: учеб. / Т.А. Аверина, С.А. Баркалов, Е.В. Баутина, С.А. Колодяжный. - Старый Оскол, 2020.

5. Application of Digital Twins in the Management of Socio-Economic Systems / S.A. Barkalov, D.V. Dorofeev, I. Fedorova, A.I. Polovinkina // E3S Web of Conferences. XXII International Scientific 
Conference Energy Management of Municipal Facilities and Sustainable Energy Technologies (EMMFT-2020). - 2021. - P. 11001. DOI: 10.1051/e3sconf/202124411001

6. Национальный центр государственно-частного партнерства ВЭБ РФ. - https://pppcenter.ru/ (дата обращения: 13.06.2021).

7. Паспорт начиональной программы «Цифровая экономика Российской Федерачии».

8. Bondarenko, Yu.V. Aggregated Multi-Criteria Model of Enterprise Management Engineering, Taking into Account the Social Priorities of the Region / Yu.V. Bondarenko, T.A. Sviridova, T.A. Averina // IOP Conference Series: Materials Science and Engineering. International Workshop "Advanced Technologies in Material Science, Mechanical and Automation Engineering - MIP: Engineering - 2019". Krasnoyarsk Science and Technology City Hall of the Russian Union of Scientific and Engineering Associations. - 2019. - P. 42045. DOI: 10.1088/1757-899X/537/4/042045

9. Максимов, В.В. Государственно-частное партнерство в транспортной инфраструктуре: критерии оценки концессионных соглашений / В.В. Максимов. - М.: Альпина Паблишер, 2018. $389 c$.

10. Технологическое предпринимательство. Движение вперед - рост и развитие: учеб. / Т.А. Аверина, С.А. Баркалов, Е.В. Баутина, С.А. Колодяжный. - Старый Оскол, 2020.

11. Информационно-аналитический обзор Министерства экономического развития о развитии государственно-частного партнерства в РФ. - https://www.economy.gov.ru/material/file/ 6b5f12f3140cf044f1f715d18dfdef0a/gchp\%2021.02.2020.pdf.pdf (дата обращения: 12.06.2021).

12. Картографическая программа МарINFO. - http://mapinfo.ru (дата обращения: 12.06.2021).

13. Картографическая программа Рапогата. - https://gisinfo.ru (дата обращения: 12.06.2021).

14. Геодезическая программа Microstation. - https://www.bentley.com/ru (дата обращения: 12.06.2021)

15. Косарева, Е.Н. Государственно-частное партнерство в жилищно-хозяйственной сфере / Е.Н. Косарева. - М.: Проспект, 2018. - 166 с.

16. Надыров, И.О. Описание концепции интерактивной карты / И.О. Надыров // Вестник СГУГТ (Сибирского государственного университета геосистем и технологий). - 2011. № 1 (14). - C. 62-68.

17. Соколов, И.А. Государственно-частное партнерство как инструмент поддержки инноваций / И.А. Соколов. - М.: Наука, 2020. - 806 с.

Аверина Татьяна Александровна, канд. техн. наук, доцент, доцент кафедры управления, Воронежский государственный технический университет, г. Воронеж; ta_averina@mail.ru.

Баркалов Сергей Алексеевич, д-р техн. наук, профессор, заведующий кафедрой управления, Воронежский государственный технический университет, г. Воронеж; bsa610@yandex.ru.

Лаврова Юлия Сергеевна, аспирант кафедры управления, Воронежский государственный технический университет, г. Воронеж.

Поступила в редакцияю 23 июня 2021 г. 


\title{
DIGITALIZATION OF PUBLIC-PRIVATE PARTNERSHIP ACTIVATION PROCESSES AS A TOOL FOR ATTRACTING INVESTMENT
}

\author{
T.A. Averina, ta_averina@mail.ru, \\ S.A. Barkalov, bsa610@yandex.ru, \\ Yu.S. Lavrova \\ Voronezh State Technical University, Voronezh, Russian Federation
}

\begin{abstract}
Currently, one of the promising areas of economic development is digitalization in general and the formation of a high-quality information infrastructure in particular. This is especially true for the processes of activating public-private partnership - mutually beneficial interaction between the state and business. Due to the pandemic, investors are working with their portfolio more carefully, and it becomes more difficult to attract private funds. The purpose of the study is to analyze the information environment for PPP projects, namely, to assess its attractiveness and transparency for investors. The objectives are to analyze the distribution of concession agreements by investment volume, identify problem areas in the implementation of public-private partnership programmes of the Russian Federation, describe measures that contribute to improving the efficiency of publicprivate interaction. General scientific methods of analysis and synthesis were used in the work. The authors relied on such materials as current publications of domestic and foreign scientists on the research topic, materials of All-Russian and international management conferences, electronic reports of research centers and official statistics provided by government agencies. As a result, an interactive map is described rating of cities by the level of development of project activities in the field of public-private partnership. The interactive map is a powerful tool of digital transformation, unlike the annual published electronic and paper reports, more accurately reflects the situation on the PPP projects market at the current time, that is, the information remains relevant for each of the requests of each subsequent user. The article also presents the results of a comparative analysis of popular mapping programs as a definition of the most effective and sustainable platform for creating a service. By transforming the traditional information infrastructure in this way, it is possible to increase the investment attractiveness of subjects, and therefore affect the quality of life of residents of both individual cities and the whole country.
\end{abstract}

Keywords: public-private partnership, investment attractiveness, digitalization, interactive maps.

\section{References}

1. Averina T.A., Lavrova Y.S., Myshovskaya L.P. [Analysis of the possibilities of digital transformation of housing and communal services management on the example of online services]. Theory of Active Systems - 50 years. Materials of the international scientific and practical conference, 2019, pp. 290-297. (in Russ.)

2. Avdeeva E.A., Averina T.A., Lavrova Yu.S. [Interactive maps as an element of the digital infrastructure of housing and communal services]. Theory and practice of economics and entrepreneurship. Proceedings of the XVIII All-Russian Scientific and Practical Conference with international participation. Simferopol, 2021, pp. 199-201. (in Russ.)

3. Barkalov S.A., Burkov V.N., Perevalova O.S., Averina T.A. [Decision-making mechanisms in the digital economy]. Trends in the development of the Internet and digital economy. Proceedings of the III All-Russian Scientific and Practical Conference with international participation, 2020, pp. 12-16. (in Russ.)

4. Averina T.A., Barkalov S.A., Bautina E.V., Kolodyazhny S.A. Tekhnologicheskoye predprinimatel'stvo. C chego nachat' - pervyye shagi: ucheb. [Technological entrepreneurship. Where to start the first steps: Textbook]. Stary Oskol, 2020.

5. Barkalov S.A., Dorofeev D.V., Fedorova I., Polovinkina A.I. Application of Digital Twins in the Management of Socio-Economic Systems. E3S Web of Conferences. XXII International Scientific Conference Energy Management of Municipal Facilities and Sustainable Energy Technologies (EMMFT-2020), 2021, p. 11001. DOI: 10.1051/e3sconf/202124411001 
6. Natsional'nyy tsentr gosudarstvenno-chastnogo partnerstva VEB RF [National Center for PublicPrivate Partnership of the VEB Russian Federation]. Available at: https://pppcenter.ru/ (accessed 13.06.2021).

7. Pasport natsional'noy programmy "Tsifrovaya ekonomika Rossiyskoy Federatsii" [Passport of the national program "Digital Economy of the Russian Federation"].

8. Bondarenko Yu.V., Sviridova T.A., Averina T.A. Aggregated Multi-Criteria Model of Enterprise Management Engineering, taking into Account the Social Priorities of the Region. IOP Conference Series: Materials Science and Engineering. International Workshop "Advanced Technologies in Material Science, Mechanical and Automation Engineering - MIP: Engineering - 2019”. Krasnoyarsk Science and Technology City Hall of the Russian Union of Scientific and Engineering Associations, 2019, p. 42045. DOI: $10.1088 / 1757-899 X / 537 / 4 / 042045$

9. Maksimov V.V. Gosudarstvenno-chastnoye partnerstvo $v$ transportnoy infrastrukture: kriterii otsenki kontsessionnykh soglasheniy [Public-private partnership in transport infrastructure: criteria for evaluating concession agreements]. Moscow, Alpina Publisher, 2018. 389 p.

10. Averina T.A., Barkalov S.A., Bautina E.V., Kolodyazhny S.A. Tekhnologicheskoye predprinimatel'stvo. Dvizheniye vpered - rost $i$ razvitiye: ucheb. [Technological entrepreneurship. Moving forward - growth and development: Textbook]. Stary Oskol, 2020.

11. Informatsionno-analiticheskiy obzor Ministerstva ekonomicheskogo razvitiya o razvitii gosudarstvenno-chastnogo partnerstva $v R F$ [Information and analytical review of the Ministry of Economic Development on the development of public-private partnership in the Russian Federation]. Available at: https://www.economy.gov.ru/material/file/6b5f12f3140cf044f1f715d18dfdef0a/gchp\%2021.02.2020.pdf.pdf (accessed 12.06.2021).

12. Kartograficheskaya programma MapINFO [MapInfo mapping program]. Available at: http://mapinfo.ru (accessed 12.06.2021).

13. Kartograficheskaya programma Panorama [Panorama map program]. Available at: https://gisinfo.ru (accessed 12.06.2021).

14. Geodezicheskaya programma Microstation [Geodesic program Microstation]. Available at: https://www.bentley.com/ru (accessed 12.06.2021).

15. Kosareva E.N. Gosudarstvenno-chastnoye partnerstvo $v$ zhilishchno-khozyaystvennoy sfere [Public-private partnership in the housing and economic sphere]. Moscow, Prospekt Publ., 2018. 166 p.

16. Nadyrov I.O. [Description of the interactive map concept]. Bulletin of SSUGT (Siberian State University of Geosystems and Technologies), 2011, no. 1 (14), pp. 62-68. (in Russ.)

17. Sokolov I.A. Gosudarstvenno-chastnoye partnerstvo kak instrument podderzhki innovatsiy [Public-private partnership as a tool for supporting innovation]. Moscow, Nauka Publ., 2020. 806 p.

Received 23 June 2021

\section{ОБРАЗЕЦ ЦИТИРОВАНИЯ}

Аверина, Т.А. Цифровизация процессов активизации государственно-частного партнерства как инструмент привлечения инвестиций / Т.А. Аверина, С.А. Баркалов, Ю.С. Лаврова // Вестник ЮУрГУ. Серия «Компьютерные технологии, управление, радиоэлектроника». - 2021. - Т. 21, № 4. - С. 148-155. DOI: $10.14529 /$ ctcr210413

\section{FOR CITATION}

Averina T.A., Barkalov S.A., Lavrova Yu.S. Digitalization of Public-Private Partnership Activation Processes as a Tool for Attracting Investment. Bulletin of the South Ural State University. Ser. Computer Technologies, Automatic Control, Radio Electronics, 2021, vol. 21, no. 4, pp. 148-155. (in Russ.) DOI: $10.14529 /$ ctcr210413 